\title{
SEROSCREENING OF LACTATING CATTLE FOR COXIELLOSIS BY TRANS-PCR AND COMMERCIAL ELISA IN KERALA, INDIA
}

\author{
Pankaj Dhaka ${ }^{1}$, Satyaveer Singh Malik ${ }^{1 *}$, Jay Prakash Yadav ${ }^{1}$, Manesh Kumar ${ }^{1}$, Jess Vergis ${ }^{1}$, \\ Radhakrishna Sahu ${ }^{1}$, Lijo John², Sukhadeo Baliram Barbuddhe ${ }^{3}$, Deepak B. Rawool ${ }^{1}$ \\ ${ }^{1}$ Division of Veterinary Public Health, Indian Veterinary Research Institute, Izatnagar, Uttar Pradesh, India, Pin- 243122. \\ ${ }^{2}$ Department of Veterinary Biochemistry, College of Veterinary and Animal Sciences, Pookode, Lakkidi P.O., Wayanad, Kerala, India, Pin- 673576. \\ ${ }^{3}$ National Research Centre on Meat, Chengicherla, Boduppal Post, Hyderabad, Telangana, India, Pin- 500092.
}

Received - May 27, 2017; Revision - June 27, 2017; Accepted - June 29, 2017

Available Online - June 30, 2017

DOI: http://dx.doi.org/10.18006/2017.5(3).377.383

\begin{tabular}{l} 
KEYWORDS \\
Cattle \\
Coxiella burnetii \\
ELISA \\
Q fever \\
trans-PCR \\
Zoonoses \\
\hline
\end{tabular}

\begin{abstract}
The sero-epidemiology of Coxiella burnetii infection in domestic ruminants, which are considered as prime reservoirs, remains largely neglected and underreported in various states of India. The present study was aimed to assess coxiellosis among lactating cattle $(n=134)$ based on their seroscreening at household level in Malappuram district of Kerala, India. On testing the cattle sera by trans-PCR targeting IS1111 gene of $C$. burnetii for the pathogen detection as well as by a commercial ELISA kit for the detection of antibodies against $C$. burnetii, the acute infection was noticed in 01 out of 134 animals $(0.75 \%)$ that tested positive in trans-PCR assay while 06/134 (4.5\%) animals indicated a persistent focalised infection based on their positivity in ELISA. Therefore, we conclude and recommend that the use of trans-PCR along with a serological assay like ELISA on serum samples is indispensable for early diagnosis of acute cases of coxiellosis in animals as well as to get a realistic assessment of the disease burden based on seroprevalence. This study seems to be the first epidemiological survey to highlight the hidden threat of coxiellosis among cattle population in Kerala, a southern state of India. However, other domestic and wild animals including cattle as well as their human contacts at high-risk need to be investigated through a large scale and multicentric epidemiological study for making a realistic assessment of the associated risk factors and to unmask the zoonotic potential of $C$. burnetii infection in the country.
\end{abstract}

\section{* Corresponding author}

E-mail: svsmalik@gmail.com (Dr. Satyaveer Singh Malik)

Peer review under responsibility of Journal of Experimental Biology and Agricultural Sciences.

Production and Hosting by Horizon Publisher India [HPI] (http://www.horizonpublisherindia.in/).

All rights reserved.
All the article published by Journal of Experimental Biology and Agricultural Sciences is licensed under a Creative Commons Attribution-NonCommercial 4.0 International License Based on a work at www.jebas.org. 


\section{INTRODUCTION}

Q fever, which is ranked one among the top 13 global priority zoonoses (Grace et al., 2012), is a highly infectious but underreported zoonosis of great public health importance having worldwide distribution with the exception of Antarctica and New Zealand (Arricau-Bouvery \& Rodolakis, 2005; Larson et al., 2016; Eldin et al., 2017). The causative agent Coxiella burnetii is a Gram-negative and obligate intracellular bacterium, which is considered as an extremely infectious and most contagious pathogen that requires bio-safety level-3 handling facilities (Grace et al., 2012), as even a single cell of the bacterium can cause infection (Honarmand, 2012). Accordingly, the pathogen is classified as category ' $\mathrm{B}$ ' agent and a potential bioterrorism agent by Centers for Disease Control and Prevention (CDC) (Madariaga et al., 2003). Moreover, the spore-like form of the agent is highly resistant to adverse environment and capable of surviving for long in soil (Evstigneeva et al., 2004). Domestic ruminants are the best known reservoir of $C$. burnetii and the pathogen shedding occurs primarily during the abortion or normal delivery of infected animal which can infect a large variety of animals, humans, birds, and arthropods (Parker et al., 2006; McCaughey et al., 2010). Q fever in humans is primarily transmitted through inhalation of dust contaminated with infected animal birth products or secretions, such as the placenta (Parker et al., 2006). In recent times, the heightened awareness of $\mathrm{Q}$ fever as an important zoonosis was linked to dairy goat farms near densely populated areas that presumably involved human exposure via a windborne route that resulted in the world's largest known reported Q fever outbreak during the period of 2007-2010 in the Netherlands, with an involvement of more than 4,000 human cases (Van der Hoek et al., 2010; Schimmer et al, 2012).

In diagnostic arena, the recent advances made in rapid and accurate diagnostic methods, such as nucleic acid detection using polymerase chain reaction (PCR) assay and serological screening by enzyme-linked immunosorbent assay (ELISA) for detection of antibodies helped the researchers to better describe the characteristics of bacterial shedding routes and the antibody responses during both experimental and natural infections (Berri et al., 2000; Arricau-Bouvery \& Rodolakis, 2005; Guatteo et al., 2007). The sensitivity of the ELISA has been estimated to be 95.2\% for the detection of IgG in C. burnetii infection (WegdamBlans et al., 2012), whereas, in other study the specificity of the ELISA has been estimated to $98.44 \%$ (Vaidya et al., 2010). However, the serological tests have proven to be inadequate for detecting $\mathrm{Q}$ fever infections in the very early phase of the disease, when antibody levels are low or developing; hence, the PCR for nucleic acid detection is indispensable for early diagnosis of acute Q fever (Schneeberger et al., 2010), with the most preferred target as the transposable repetitive insertion element sequence $I S 1111$ of C. burnetii, which is present in about 20 copies in the C. burnetii Nine Mile genome (Denison et al., 2007).
Coxiellosis in cattle usually remains asymptomatic (Rodolakis, 2009; Ortega-Mora, 2012), however, it may cause sporadic reproductive problems such as abortion (Ortega-Mora, 2012), metritis (Arricau-Bouvery \& Rodolakis, 2005) and mastitis (Barlow et al., 2008). The infected animals primarily shed large amount of bacteria during parturition, as high as $10^{9}$ organisms per gram of placenta (Bouvery et al., 2003), besides intermittently excreting them in milk, feces, urine and vaginal mucus for longer periods that may pose a serious health risk to their human contacts (Guatteo et al., 2006; Rodolakis et al., 2007). Consequently, Q fever is predominantly considered as an occupational disease of veterinarians, farmers, abattoir workers, meat handlers, shearers, tanners and laboratory workers (Madariaga et al., 2003).

Globally, the prevalence of coxiellosis in cattle has been assessed as $20 \%$ and $38 \%$ at the individual and herd level, respectively (Guatteo et al., 2011). However, the epidemiological studies on $\mathrm{Q}$ fever in India in general are very limited, while the research on associated risk factors and disease dynamic trends in particular are almost negligible, which can be primarily attributed to the limited diagnostic capacities and gross neglect of the disease on account of lack of the clinical curiosity among the physicians and veterinary professionals (Vaidya et al., 2010; Malik et al., 2013; Stephen et al., 2014; Kumar at al., 2017; Mohan et al., 2017). In fact, during the past 60 years only about 25 publications on human and animal Q fever from India are available in international databases (Kumar et al., 2017), including the two recent reports on bovine coxiellosis from northern part of India (Vaidya et al., 2010; Das et al., 2014), and a sole report on coxiellosis in ovines (Stephen et al., 2014) from southern part of India. However, no systematic study on bovine coxiellosis from southern part of India has been documented so far. In order to address this knowledge gap, the present study was envisaged to assess the $C$. burnetii infection in lactating cattle at household level in Malappuram district of Kerala, India.

\section{Materials and methods}

\subsection{Study areas and samples}

The present study was carried out during January, 2017 to May, 2017 in the different regions of Malappuram district, Kerala, India (Figure 1), wherein lactating cross-bred cattle $(n=134)$ were investigated for coxiellosis at household levels, with a maximum of 03 cattle per house and a known history of reproductive disorders in 5.97\% (8/134) animals. None of the animals included in the study had received vaccination for $\mathrm{Q}$ fever. The blood samples from the jugular vein of cattle were taken into $10 \mathrm{ml}$ vacuum tubes (Vacutainer, Becton Dickinson, Franklin Lakes, USA) under the supervision of veterinary officials and with the proper consent of owners, stored in a refrigerated bag, brought to the laboratory, centrifuged at $2500 \times g$ for $10 \mathrm{~min}$ for separating serum, split in two aliquots, and finally stored at $-20{ }^{\circ} \mathrm{C}$, within 12 hours of sample collection. 


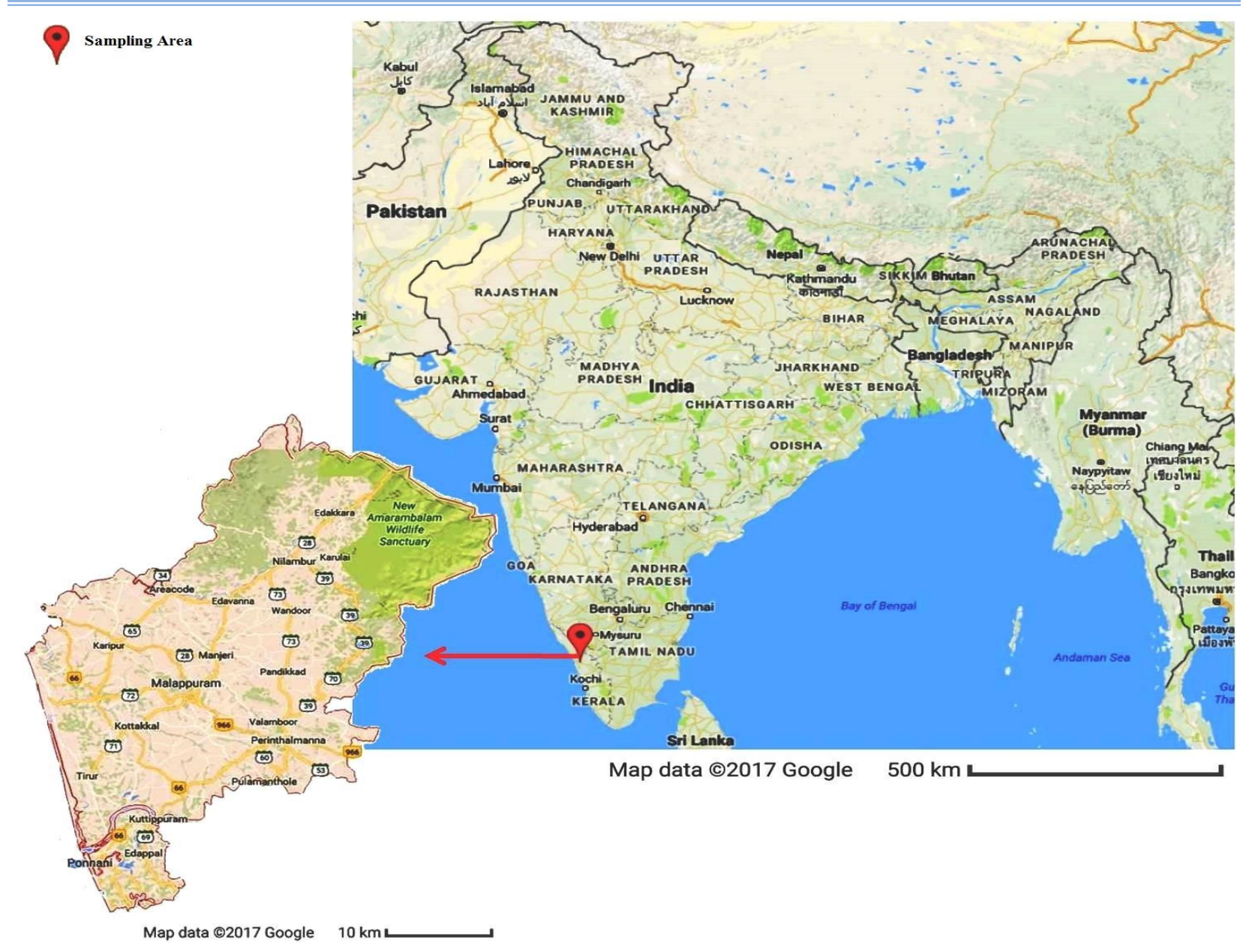

Figure 1 Inset picture (lower left) showing the sampling area of Malappuram district of Kerala, India

\subsection{Seroscreening of cattle for coxiellosis by ELISA}

A commercial indirect ELISA Kit (Bio-X Diagnostics, Rochefort, Belgique) for detecting the antibodies against phase-I and phase-II of $C$. burnetii was employed in the study as per the manufacturer's instructions for screening the cattle sera. In brief, the test sera along with positive and negative controls were diluted to 1:100 using dilution buffer and distributed in duplicates in a 96-wells microtitre plate pre-coated with phase-I and phase-II antigens of $C$. burnetii, and incubated at $21^{\circ} \pm 3^{\circ} \mathrm{C}$ for one hour. The wells were washed thrice using $300 \mu \mathrm{L}$ of wash solution provided, added with $100 \mu \mathrm{L}$ of the diluted conjugate solution (1:50) per well, covered with lid, and incubated for 1 hour at $21^{\circ} \mathrm{C} \pm 3^{\circ} \mathrm{C}$. The wells were again washed thrice using $300 \mu \mathrm{L}$ of wash solution, added with $100 \mu \mathrm{L}$ chromogen per well, and the uncovered plate was incubated in dark for 10 minutes at $21^{\circ} \mathrm{C} \pm 3^{\circ} \mathrm{C}$. Finally, $50 \mu \mathrm{L}$ stop solution was added per well to stop the reaction and the optical densities were measured at $450 \mathrm{~nm}$ (Multiskan GO, ThermoFisher Scientific, USA). The results were interpreted by calculating the coefficient of serum samples as per the given formula:
Sample's Coefficient $=($ OD sample - OD negative serum $) /(O D$ positive serum - OD negative serum) $x 100$

A sample was considered negative, if its coefficient was less than $37 \%$, and positive, if the coefficient was $\geq 37 \%$.

\subsection{Pathogen detection in cattle sera by trans-PCR assay}

The detection of the pathogen in serum samples of cattle was carried out employing trans-PCR targeting the IS1111 gene of $C$. burnetii. The DNA extraction from the serum samples was carried out by using DNeasy Blood and Tissue Kit (Qiagen, USA) as per the manufacturer's instructions. The extracted DNA was subjected to the standardized trans-PCR assay employing the trans-1 (5'TAT GTA TCC ACC GTA GCC AGT C-3') and trans-2 (5'-CCC AAC AAC ACC TCC TTA TTC-3') oligonucleotides, which were got synthesized (Eurofins Genomics India Pvt. Limited, Bangalore) for amplification of $687 \mathrm{bp}$ fragment corresponding to the transposon-like repetitive element of $C$. burnetii in a test sample. 
The PCR assay protocol (Berri et al., 2000; Vaidya et al., 2010) was standardized with suitable modifications. Briefly, $25 \mu \mathrm{L}$ of reproductive disorders and seropositivity for $C$. burnetii infection in cattle (Table 1).

Table 1 Statistical analysis for correlation between reproductive disorders and seropositivity of $C$. burnetii infection in cattle by using chisquare test

\begin{tabular}{|c|c|c|c|}
\hline \multirow[t]{2}{*}{ Category } & \multicolumn{2}{|c|}{ Serological profile employing ELISA } & \multirow[t]{2}{*}{ Statistical analysis (P-value) } \\
\hline & Seropositive & Seronegative & \\
\hline $\begin{array}{l}\text { Cattle with reproductive disorders } \\
{[5.97 \%(8 / 134)]}\end{array}$ & 04 & 04 & $\begin{array}{l}\text { Chi-square test: } \mathrm{P}<0.001 \\
\text { Phi: } \mathrm{P}<0.001\end{array}$ \\
\hline $\begin{array}{l}\text { Cattle without reproductive disorders } \\
\text { [94.03\% (126/134)] }\end{array}$ & 02 & 124 & $\begin{array}{l}\text { Cramer's V: } \mathrm{P}<0.001 \\
\text { Contingency Coefficient: } \mathrm{P}<0.001\end{array}$ \\
\hline
\end{tabular}

PCR reaction mixture included $2.5 \mu \mathrm{L}$ of $10 \mathrm{X}$ PCR buffer $(100$ $\mathrm{mM}$ Tris- $\mathrm{HCl}$ buffer, $\mathrm{pH} 8.3$ containing $500 \mathrm{mM} \mathrm{KCl}, 15 \mathrm{mM}$ $\mathrm{MgCl}_{2}$ and $0.01 \%$ gelatin), $200 \mu \mathrm{M}$ of dNTP mix, $3.0 \mathrm{mM}$ of $\mathrm{MgCl}_{2}, 2.0 \mu \mathrm{M}$ of each primers, 0.5 Unit of Taq DNA polymerase (3B Black Bio, Spain), $5 \mu \mathrm{L}$ of DNA template and sterilized nuclease-free water to make up the volume. The DNA of $C$. burnetii Nine Mile 1 strain was used as a positive control. The cycling conditions for PCR included an initial denaturation at $95^{\circ} \mathrm{C}$ for 4 min followed by 35 cycles, each consisting of denaturation at $94^{\circ} \mathrm{C}$ for 30 s, annealing at $52^{\circ} \mathrm{C}$ for 30 s and extension at $72^{\circ} \mathrm{C}$ for $1 \mathrm{~min}$. The final stage of the reaction included an extension of 10 min at $72^{\circ} \mathrm{C}$ was performed in a Thermal cycler (Eppendorf, $\mathrm{GmbH}$, Germany). The amplified PCR products along with $100 \mathrm{bp}$ DNA marker ladder were resolved in $1 \%$ agarose gel containing ethidium bromide $\left(10 \mu \mathrm{gmL}^{-1}\right)$ by electrophoresis using TrisAcetate-EDTA as running buffer and visualized by gel documentation system employing GelDoc-lt 310 (UVP, UK). All the materials contaminated with ethidium bromide were disposed of properly according to the institutional guidelines.

\subsection{Statistical analysis}

The correlation between reproductive disorders in cattle and $C$. burnetii infection were statistically analyzed by employing chisquare test including Cramer's V, Phi and Contingency coefficient, in order to find the degree of association between the categorical variables using SPSS software, 22.0 version.

\section{Results:}

In present study, out of 134 cattle serum samples tested by the commercial ELISA kit, $4.5 \%$ (06/134) revealed positivity for antiC. burnetii antibodies, while the DNA of pathogen could be detected in 01 sample by trans-PCR. It is noteworthy that the only positive serum sample in trans-PCR was also positive for anti- $C$. burnetii antibodies in ELISA.

Out of the 06 cattle that were found seropositive for coxiellosis, $66.66 \%(04 / 06)$ had a history of reproductive disorders. On analysis of the results by using chi-square test, a statistically significant correlation $(\mathrm{P}<0.001)$ was observed between the

\section{Discussion}

In India, which is bestowed with the highest number of livestock wealth (512 million) in the world, livestock farming is considered as a central source of their livelihood for $58 \%$ out of its total $72 \%$ rural population, i.e., over 100 million (Bhatt \& Smith, 2012; DADF Annual report 2014-15). However, frequent outbreaks of livestock diseases including zoonoses coupled with the constraints related to feeding, breeding, health and management remains a major hurdle in harnessing the full production potential of livestock. In this context, role and status of reservoirs of coxiellosis among ruminants, which are considered to serve as a main source for this largely masked and grossly underreported zoonosis, remains rather unexplored barring a few studies in India (Vaidya et al., 2010; Malik et al., 2013; Stephen et al., 2014; Mohan et al., 2017).

The observed seropositivity of $4.5 \%$ (06/134) cattle for $C$. burnetii in Malappuram district of Kerala, India as well as the detection of pathogen in a serum sample by trans-PCR in the present study corroborates with an earlier study wherein the seropositivity of 4.54\% was recorded in cattle from Bareilly, U.P. (Das et al., 2014). However, it was well below the range of 12.78 to $29.9 \%$ reported in the cattle from northern parts of country by other workers (Joshi et al., 1978; Vaidya et al., 2010), which may be attributed to the investigation of animals at household level, with not more than 3 cattle per house examined in the present study. On contrary, studies involving large cattle herd size with intensive farming practices were found to have a positive association with $C$. burnetii infection (McCaughey et al., 2010; Ryan et al., 2011; Paul et al., 2012; Agger \& Paul, 2014; Boroduske et al., 2017). The positivity of a serum sample in both trans-PCR and ELISA points to an active cycling of the pathogen within the herd/animal, where the animals get infected and seroconverts frequently as described by other researchers (Freick et al., 2017).

The acute infection noticed in 01 out of 134 animals $(0.75 \%)$ by trans-PCR assay as well as the persistent focalised infection in 06/134 (4.5\%) animals by ELISA in our study has unmasked the otherwise hidden risk associated with the cattle reservoirs that may 
potentially pose a threat to other animal species or even to their human contacts, especially in view of the aerosol transmission, high infectivity and high stability of the pathogen that may be present in great numbers in the milk, blood, excreta, placenta, vaginal discharges and other tissues of infected animals (Parker et al, 2006; Porter et al., 2011; Boroduske et al., 2017; Eldin et al., 2017). In this context, the intermittent shedding of the bacteria in the milk of infected lactating cattle for a prolonged period ranging from 13 months (Arricau-Bouvery \& Rodolakis, 2005) to 32 months (Angelakis \& Raoult, 2010) assumes a special significance, as it constitutes a persistent and potent source of infection.

Based on findings of this study, we endorse the combined use of trans-PCR for pathogen detection along with a serological assay for antibody detection as an ideal diagnostic approach for seroscreening of animals for coxiellosis, which has been recommended earlier for the diagnostic work-up of a patient with suspected acute Q fever (Schneeberger et al., 2010).

C. burnetii infection in cattle can be the cause of a limited percentage of fetal losses and stillbirths (Muskens et al., 2012), and in some cases dead or weak offspring, followed by recovery without complications (Ortega-Mora, 2012). Moreover, it has also been suggested to play a role in infertility or problems such as metritis in cattle (Ortega-Mora, 2012). In present study, a positive correlation was observed between sero-positivity and history of reproductive disorders in lactating cattle. These observations draw strength from the earlier studies wherein the pathogen has been isolated from the samples of blood (Das et al., 2014) and genital organs (Ho et al., 1995; Vaidya et al., 2010) of bovines with the history of reproductive disorders. However, the small sample size and non-consideration of other causal factors associated with reproductive disorders in our study limits us to arrive at any definitive conclusion, especially in the absence of the clear demonstration of any effect of $C$. burnetii infection (GarciaIspierto et al., 2014) or seropositivity and shedding (Freick et al., 2017) on the parameters of reproduction in a dairy herd.

In conclusion, the present study albeit limited in its scale and sample size, appears to be the first of its kind in revealing the status of $C$. burnetii infection in lactating cattle in Kerala state located in the southern region of India. Moreover, it also highlighted the likely risk of contracting the infection from these infected cattle by human contacts and other animal species. Therefore, such studies of larger magnitude and dimensions covering other states are required to estimate the precise disease burden in ruminant population and their human contacts as well as to identify the associated risk factors. Moreover, in view of the important and far reaching implications of $\mathrm{Q}$ fever for both livestock production and public health, as has been witnessed in the Netherland outbreak, a large scale epidemiological investigation-cum-awareness programme is warranted so as to make medicos, veterinarians and high risk groups clinically aware and curious for considering $\mathrm{Q}$ fever in the differential diagnosis and management of reproductive disorders and mastitis in livestock, screening of ruminants and pets as potential reservoirs by reliable diagnostic tests, as well as in cases of atypical pneumonia, hepatitis, endocarditis, abortions and chronic fatigue syndrome, especially in their human contacts; so as to make a realistic assessment of this largely masked, neglected and under reported zoonosis in the country.

\section{Acknowledgements}

The authors thank Director, ICAR-Indian Veterinary Research Institute, Izatnagar for providing necessary facilities to undertake the research. We are grateful to Dr. Eric Ghigo, URMITE-IRD, Faculté de Médecine, France for providing the DNA of standard $C$. burnetii Nine Mile strain. We also thank Mr. K. K. Bhatt for his excellent technical assistance.

Conflict of interest: The authors declare that they have no conflict of interests.

\section{References:}

Agger JF, Paul S (2014) Increasing prevalence of Coxiella burnetii seropositive Danish dairy cattle herds. Acta Veterinaria Scandinavica 56: 46. doi:10.1186/s13028-014-0046-2.

Angelakis E, Raoult D (2010) Q fever. Veterinary Microbiology 140: 297-309. doi.org/10.1016/j.vetmic.2009.07.016.

Arricau-Bouvery N, Rodolakis A (2005) Is Q fever an emerging or re-emerging zoonosis?. Veterinary Research 36: 327-349.

Barlow J, Rauch B, Welcome F, Kim SG, Dubovi E, Schukken Y (2008) Association between Coxiella burnetii shedding in milk and subclinical mastitis in dairy cattle. Veterinary Research 39: 1. doi:10.1051/vetres:2007060.

Berri M, Laroucau K, Rodolakis A (2000) The detection of Coxiella burnetii from ovine genital swabs, milk and fecal samples by the use of a single touchdown polymerase chain reaction. Veterinary $\quad$ Microbiology 72: 285-293. doi.org/10.1016/S0378-1135(99)00178-9.

Bhatt PM, Smith J (2012) Turning obstacles into opportunities: The livestock sector scenario. Available on https://ilriasia.wordpress.com/2012/07/07/turning-obstacles-intoopportunities access on 25th May, 2017.

Boroduske A, Trofimova J, Kibilds J, Papule U, Sergejeva M, Rodze I, Grantina-Ievina L (2017) Coxiella burnetii (Q fever) infection in dairy cattle and associated risk factors in Latvia. Epidemiology $\quad \& \quad$ Infection 1-9. doi.org/10.1017/S0950268817000838. 
Bouvery NA, Souriau A, Lechopier P, Rodolakis A (2003) Experimental Coxiella burnetii infection in pregnant goats: excretion routes. Veterinary Research 34: 423-433. doi:10.1051/vetres:2003017.

Das DP, Malik SVS, Rawool DB, Das S, Shoukat S, Gandham RK, Saxena S, Singh R, Doijad SP, Barbuddhe SB (2014) Isolation of Coxiella burnetii from bovines with history of reproductive disorders in India and phylogenetic inference based on the partial sequencing of IS1111 element. Infection, Genetics and Evolution 22: 67-71. doi.org/10.1016/j.meegid.2013.12.017.

Denison AM, Thompson HA, Massung RF (2007) IS 1111 insertion sequences of Coxiella burnetii: characterization and use for repetitive element PCR-based differentiation of Coxiella burnetii isolates. BMC Microbiology 7: 91. doi: 10.1186/14712180-7-91.

Department of Animal Husbandry Dairying \& Fisheries (DAHD) Annual report 2014-15. p.172. Available on http://aipvt.vci.nic.in/REPORT.pdf access on 25th May, 2017.

Eldin C, Mélenotte C, Mediannikov O, Ghigo E, Million M, Edouard S, Mege JL, Maurin M, Raoult D (2017) From Q fever to Coxiella burnetii infection: a paradigm change. Clinical Microbiology Reviews 30: 115-190. doi: 10.1128/CMR.00045-16.

Evstigneeva AS, Komarova AI, Fetisova NF, Makarova VA, Tarasevich IV (2004) Survival of Coxiella burnetii in soil. Zhurnal mikrobiologii epidemiologii i immunobiologii 6: 57-59.

Freick M, Enbergs H, Walraph J, Diller R, Weber J, Konrath A (2017) Coxiella burnetii: Serological reactions and bacterial shedding in primiparous dairy cows in an endemically infected herd-impact on milk yield and fertility. Reproduction in Domestic Animals 52: 160-169. doi: 10.1111/rda.12878.

Garcia-Ispierto I, Tutusaus J, López-Gatius F (2014) Does Coxiella burnetii affect reproduction in cattle? A clinical update. Reproduction in Domestic Animals 49: 529-535. doi: 10.1111/rda.12333.

Grace D, Mutua F, Ochungo P, Kruska R, Jones K, Brierley L, Lapar L, Said M, Herrero M, Phuc PM, Thao NB (2012) Mapping of poverty and likely zoonoses hotspots. Zoonoses Project 4. Report to the UK Department for International Development. International Livestock Research Institute, Nairobi, Kenya.

Guatteo R, Beaudeau F, Berri M, Rodolakis A, Joly A, Seegers H (2006) Shedding routes of Coxiella burnetii in dairy cows: implications for detection and control. Veterinary Research 37: 827-833. doi:10.1051/vetres:2006038.

Guatteo R, Beaudeau F, Joly A, Seegers H (2007) Coxiella burnetii shedding by dairy cows. Veterinary Research 38: 849-860. doi:10.1051/vetres:2007038.
Guatteo R, Seegers H, Taurel AF, Joly A, Beaudeau F (2011) Prevalence of Coxiella burnetii infection in domestic ruminants: a critical review. Veterinary Microbioloy 149: 1-16. doi.org/10.1016/j.vetmic.2010.10.007.

Ho T, Htwe KK, Yamasaki N, Zhang GQ, Ogawa M, Yamaguchi T, Fukushi H, Hirai K (1995) Isolation of Coxiella burnetii from dairy cattle and ticks, and some characteristics of the isolates in Japan. Microbiology and Immunology 39: 663-671.

Honarmand, H (2012) Q Fever: an old but still a poorly understood disease. Interdisciplinary Perspectives on Infectious Diseases 2012.

Joshi MV, Padbidri VS, Rodrigues FM, Gupta NP (1978) Prevalence of Coxiella burnetii infection among humans and domestic animals of Rajasthan State, India. Journal of Hygiene, Epidemiology, Microbiology, and Immunology 23: 67-73.

Kumar S, Gangoliya SR, Alam SI, Patil S, Ajantha GS, Kulkarni RD, Kamboj DV (2017) First genetic evidence of Coxiella burnetii in cases presenting with acute febrile illness, India. Journal of Medical Microbiology 66: 388-390. doi:10.1099/jmm.0.000448.

Larson CL, Martinez E, Beare PA, Jeffrey B, Heinzen RA, Bonazzi M (2016) Right on Q: genetics begin to unravel Coxiella burnetii host cell interactions. Future Microbiology 11: 919-939. doi:10.2217/fmb-2016-0044.

Madariaga MG, Rezai K, Trenholme GM, Weinstein RA (2003) Q fever: a biological weapon in your backyard. The Lancet Infectious Diseases 3: 709-721.

Malik SS, Das DP, Rawool D, Kumar A, Suryawanshi RD, Negi M, Vergis J, Doijad S, Barbuddhe SB (2013) Screening of Foods of Animal Origin for Coxiella burnetii in India. Advances in Animal and Veterinary Sciences 1: 107-110. Available on http://www.nexusacademicpublishers.com/journal/4 access on 25th May, 2017.

McCaughey C, Murray LJ, McKenna JP, Menzies FD, McCullough SJ, O'neill HJ, Wyatt DE, Cardwell CR, Coyle PV (2010) Coxiella burnetii (Q fever) seroprevalence in cattle. Epidemiology and Infection 138: 2127. doi.org/10.1017/S0950268809002854.

Mohan V, Nair A, Kumar M, Dhaka P, Vergis J, Rawool DB, Malik SS (2017) Seropositivity of goats for coxiellosis in Bareilly region of U.P. India. Advances in Animal and Veterinary Sciences 5: 226-228. doi.org/10.17582/journal.aavs/2017/5.5.226.228.

Muskens J, Wouda W, Von Bannissehtwijsmuller T, Van Maanen C (2012) Prevalence of Coxiella burnetii infections in aborted fetuses and stillborn calves. The Veterinary Record 170: 260. doi: 10.1136/vr.100378. doi: 10.1136/vr.100378.

Ortega-Mora LM (2012) Is Q fever a significant cause of reproductive failure in cattle? The Veterinary Record 170: 257258. doi: 10.1136/vr.e1592. 
Parker NR, Barralet JH, Bell AM (2006) Q fever. The Lancet 367 : 679-688. doi.org/10.1016/S0140-6736(06)68266-4.

Paul S, Agger JF, Markussen B, Christoffersen AB, Agerholm JS (2012) Factors associated with Coxiella burnetii antibody positivity in Danish dairy cows. Preventive Veterinary Medicine 107: 57-64. doi.org/10.1016/j.prevetmed.2012.05.015.

Porter SR, Czaplicki G, Mainil J, Guattéo R, Saegerman C (2011) Q Fever: current state of knowledge and perspectives of research of a neglected zoonosis. International Journal of Microbiology, Article ID 248418. doi:10.1155/2011/248418.

Rodolakis A (2009) Q Fever in dairy animals. Annals of the New York Academy of Sciences. 1166: 90-93. doi: 10.1111/j.17496632.2009.04511.x.

Rodolakis A, Berri M, Hechard C, Caudron C, Souriau A, Bodier CC, Blanchard B, Camuset P, Devillechaise P, Natorp JC, Vadet JP (2007) Comparison of Coxiella burnetii shedding in milk of dairy bovine, caprine, and ovine herds. Journal of Dairy Science 90: 5352-5360. doi.org/10.3168/jds.2006-815.

Ryan ED, Kirby M, Collins DM, Sayers R, Mee JF, Clegg T (2011) Prevalence of Coxiella burnetii (Q fever) antibodies in bovine serum and bulk-milk samples. Epidemiology and Infection 139: 1413-1417. doi.org/10.1017/S0950268810002530.

Schimmer B, Lenferink A, Schneeberger P, Aangenend H, Vellema P, Hautvast J, van Duynhoven, Y (2012) Seroprevalence and risk factors for Coxiella burnetii ( $\mathrm{Q}$ fever) seropositivity in dairy goat farmers' households in The Netherlands, 20092010. PLoS One 7 : doi.org/10.1371/journal.pone.0042364.
Schneeberger PM, Hermans MH, van Hannen EJ, Schellekens JJ, Leenders AC, Wever PC (2010) Real-time PCR with serum samples is indispensable for early diagnosis of acute $Q$ fever. Clinical and Vaccine Immunology 17:286-290. doi: 10.1128/CVI.00454-09.

Stephen S, Sangeetha B, Antony PX (2014) Seroprevalence of coxiellosis ( $\mathrm{Q}$ fever) in sheep \& goat in Puducherry \& neighbouring Tamil Nadu. The Indian Journal of Medical Research 140: 785 .

Vaidya VM, Malik SVS, Bhilegaonkar KN, Rathore RS, Kaur S, Barbuddhe SB (2010) Prevalence of Q fever in domestic animals with reproductive disorders. Comparative Immunology, Microbiology and Infectious Diseases 33: 307-321. doi.org/10.1016/j.cimid.2008.10.006.

Van der Hoek W, Dijkstra F, Schimmer B, Schneeberger PM, Vellema P, Wijkmans C, Ter Schegget R, Hackert V, Van Duynhoven Y (2010) Q fever in the Netherlands: an update on the epidemiology and control measures. Euro Surveillance 15: 19520. Available on http://www.eurosurveillance.org/ access on $25^{\text {th }}$ May, 2017.

Wegdam-Blans MCA, Wielders CCH, Meekelenkamp J, Korbeeck JM, Herremans T, Tjhie HT, Bijlmer HA, Koopmans MPG, Schneeberger PM (2012) Evaluation of commonly used serological tests for detection of Coxiella burnetii antibodies in well-defined acute and follow-up sera, Clinical and Vaccine Immunology 19: 1110-1115. doi:10.1128/CVI.05581-11. 